\title{
LAS ÉLITES CENTROAMERICANAS Y LA DIVERSIFICACIÓN DE INVERSIONES: LOS MERCADOS DE AGUA EN GUATEMALA Y COSTA RICA
}

\author{
CENTRAL AMERICAN ELITES AND INVESTMENT DIVERSIFICATION: \\ WATER MARKETS IN GUATEMALA AND COSTA RICA
}

\author{
Juan Manuel Retana Céspedes \\ Luis Diego Arias Campos \\ Daniel Torres Sandi
}

Recibido: 19/05/2019 - Aceptado: 10/09/2019

\begin{abstract}
Resumen
Se estudia la inserción de los Grupos Empresariales Diversificados en los mercados de agua en Guatemala y Costa Rica, mediante la caracterización del modelo "verde" de conservación y custodia de agua, así como los mecanismos de monetización y las nuevas estrategias del capitalismo. La diversificación de estos grupos hacia nichos económicos "verdes" responde a la plataforma facilitada especialmente por el Banco Mundial para las inversiones en agua y demás bienes de la naturaleza, dando seguridad financiera a estos negocios. Se concluye que, aunque no implica una privatización como tal, estas estrategias de monetización y acumulación en pocas manos de los derechos de uso del agua pone en riesgo la disponibilidad para otras personas, el bienestar de la naturaleza y el derecho humano fundamental de acceso a este líquido.
\end{abstract}

Palabras clave: Banco Mundial, monetización, poder, derechos humanos, hidronegocios.

\begin{abstract}
This research studies the insertion of the Diversified Business Groups in the water markets in Guatemala and Costa Rica is studied through the characterization of the "green" model of water conservation and custody, as well as the monetization mechanisms and the new strategies of capitalism. The diversification of these groups towards "green" economic niches responds to the platform provided especially by the World Bank for investments in water and other natural goods, providing financial security to these businesses. It is concluded that although it does not imply a privatization as such, these strategies of monetization and accumulation in a few hands of water use rights put at risk the availability for other people, the welfare of nature and the fundamental human right of access to this liquid.
\end{abstract}

Keywords: World Bank, monetization, power, human rights, hydrobusiness. 


\section{Introducción}

En el 2016 Wikileaks publicó un cable en el cual se reveló que Nestlé, la empresa de alimentos más grande del mundo, financió un estudio confidencial en 2009 sobre la disponibilidad de agua dulce en el planeta. Las proyecciones de dicho estudio revelaron que para 2050 el agua dulce potable estaría prácticamente agotada principalmente por los impactos de la industria cárnica. Además, recomendó tener precaución con la divulgación de los datos para evitar críticas a sus negocios y crear un mercado virtual de agua.

Este caso es parte de la evidencia que existe -y a la que se tiene acceso- en cuanto a los intereses que poseen los grupos económicos en invertir en agua por su escasez futura. Lo anterior lleva a las preguntas: ¿de qué manera han influido históricamente las agendas de los principales organismos internacionales en la conformación de mercados de agua? y ¿cómo ha sido el comportamiento de las Grupos Económicamente Diversificados (GED) centroamericanos en las inversiones sobre mercados de agua?

En la región latinoamericana en general, y la centroamericana en particular, esta situación es de interés, ya que son las que contienen más agua dulce en el planeta. Esto ha dirigido el foco de la atención de grandes conglomerados multinacionales y organismos internacionales sobre estas regiones para aprovechar los nichos económicos "verdes". No obstante, como afirman Bull y Kasahara, los GED centroamericanos han tendido a transnacionalizarse y diversificarse para competir con los transnacionales.

Este trabajo aspira a analizar la inserción de los GED en los nichos económicos "verdes", los cuales aprovechan los mecanismos de monetización de la naturaleza y la labor de los entes y organizaciones creadas con ese propósito, englobado bajo un modelo económico de libre mercado y discurso "verde", en condicionalidad cruzada con los Estados nacionales y los lineamientos de organismos internacionales.

El artículo se divide en dos partes. La primera hace un repaso especialmente por las últimas dos décadas del siglo XX y el rediseño de los mecanismos extractivistas, en los cuales se han elaborado los procesos de monetización del agua y las inversiones privadas y de los organismos internacionales en la región. En la segunda parte se analiza, sobre todo a partir de 2012, la inserción de las élites económicas centroamericanas en los mercados de agua en el contexto de las nuevas formas de administración del líquido vital.

La monetización es un concepto que se utiliza en economía y finanzas para hacer referencia al establecimiento de un activo, o un bien, como transable en alguna moneda en curso (Cambridge University). Proviene de la palabra en inglés monetize, que permite convertir, expresar o adaptar algún artículo al comercio basado en el intercambio de dinero (Oxford University). El concepto de monetizar tiene varios significados dependiendo del contexto, pero en la lógica financiera algún producto o servicio se monetiza con el fin de generar plusvalor. 
Las cuentas ambientales son parte de un estándar estadístico y un sistema de contabilidad que definen los conceptos y normas promovidas por el Banco Mundial para cuantificar el valor económico y físico de los recursos naturales, así como su importancia para la riqueza (capital total) de un país. Así, estas son implementadas paulatinamente por los bancos centrales para el análisis de su oferta, usos e interacciones con otras actividades económicas. Esta información permite el diseño de estrategias y políticas para el manejo energético y de los recursos hídricos, a la vez que monitorea los bosques y su interrelación con la economía (Banco Central de Costa Rica, 2013).

\section{Metodología}

Este trabajo es de carácter cualitativo, pero con algunos aspectos cuantitativos. Se han analizado fuentes primarias como informes, estados financieros, anuarios y rendiciones de cuentas de las empresas estudiadas, para identificar sus juntas directivas, capital accionario, sociedades anónimas vinculadas, analizar aspectos relativos a la llamada Responsabilidad Social Empresarial (RSE) e inversiones relacionadas a bosques y agua. También se revisó documentación de instituciones estatales, organismos internacionales, así como fuentes de prensa escrita, para analizar las estrategias, las políticas y los avances de la consolidación de los mercados de agua. El período de este análisis parte del 2012, debido a que en ese año se publicó el Sistema de Contabilidad Ambiental y Económica (SCAE) del Banco Mundial. En cuanto a las fuentes secundarias se han consultado principalmente artículos académicos y libros en torno a la temática de las dinámicas económicas y empresariales, la gobernanza y mercantilización del agua y el colapso ecológico antropogénico.

Las inversiones "verdes" son aquellas estrategias de diversificación que han utilizado las empresas para generar rendimientos sobre los recursos naturales y que se basan en el principio de monetización ambiental. Analizamos cuatro GED; dos de origen costarricense (Grupo Cuestamoras y Florida Ice \& Farm Co. (FIFCO)) y dos de origen guatemalteco (Corporación Castillo Hermanos y Corporación Multi-Inversiones (CMI)). La dificultad de estudiar estos grupos empresariales se debe a que no todas cotizan en bolsas nacionales de valores, además de que utilizan las figuras de sociedades anónimas y empresas "holding" para resguardar sus activos y capitales. La razón de la escogencia de estos dos países radica en que son los únicos que han incorporado las Cuentas Ambientales para agua, bosques y energía en América Central.

\section{El oro azul en la mira}

\section{Hacia la custodia del agua en América Central}

Con la crisis de la modernidad expresada en los años sesenta y setenta, uno de los temas relevantes fue la crisis ecológica. Las movilizaciones sociales a nivel mundial 
mostraron el malestar por los esquemas extractivistas del capitalismo que había llevado al extremo las destrucciones ambientales y el agotamiento de los recursos. En ese contexto, las prominentes élites y gobiernos mundiales fueron convocados en 1972 por la Organización de las Naciones Unidas (ONU) en Estocolmo para llevar a cabo la primer Cumbre de la Tierra, en la cual se discutieron las preocupaciones globales sobre el futuro del planeta basadas principalmente en los estudios científicos desarrollados por el conocido Club de Roma.

Esta Cumbre de la Tierra y otras que veremos brevemente más adelante, si bien han llamado la atención sobre las preocupantes situaciones ambientales del planeta, más bien han cooptado las consignas levantadas por los movimientos sociales del mundo y las han adaptado en función de su valor utilitario. De esta forma, la Cumbre de Estocolmo llamó a las empresas contaminadoras a responsabilizarse por los impactos ecológicos causados; sin embargo, esto ha dado pie para que estas empresas continúen con sus actividades destructivas, a cambio de multas o incentivos económicos que supuestamente compensen esas destrucciones (Rodríguez Cervantes). Por lo tanto, los esquemas de saqueo -ahora llamados "sustentables" o "verdes"- en realidad nunca han cambiado su modo de operación, sino solo su discurso (Monge Hernández), bajo el amparo de la agenda internacional de las Cumbres de la Tierra, el cual prioriza la estabilidad comercial.

Las autoridades nacionales deberian procurar fomentar la internalización de los costos ambientales y el uso de instrumentos económicos, teniendo en cuenta el criterio de que el que contamina debe, en PRINCIPIO, cargar con los costos de la contaminación, teniendo debidamente en cuenta el interés público y sin distorsionar el comercio ni las inversiones internacionales (Declaración de Rio sobre el Medio Ambiente y el Desarrollo).

Para cumplir con esa nueva agenda extractivista que procura compensar las destrucciones ecológicas con incentivos económicos, es necesario asignar valores monetarios a la naturaleza (lo cual veremos adelante) y elaborar exhaustivos inventarios de recursos, que han venido desarrollándose desde la época colonial. Esto ha dado como resultado que la región centroamericana sea sumamente valiosa por sus reservas hídricas tal y como lo muestra la Figura 1. 
Figura 1

RESERVAS DE AGUA DULCE TOTAL Y POR KILÓMETRO CUADRADO

EN AMÉRICA CENTRAL, SEGÚN PAÍS

- Reservas de agua dulce por km2 (m3) $\quad$ Reservas totales de agua dulce (millones m3)

2500000

200000

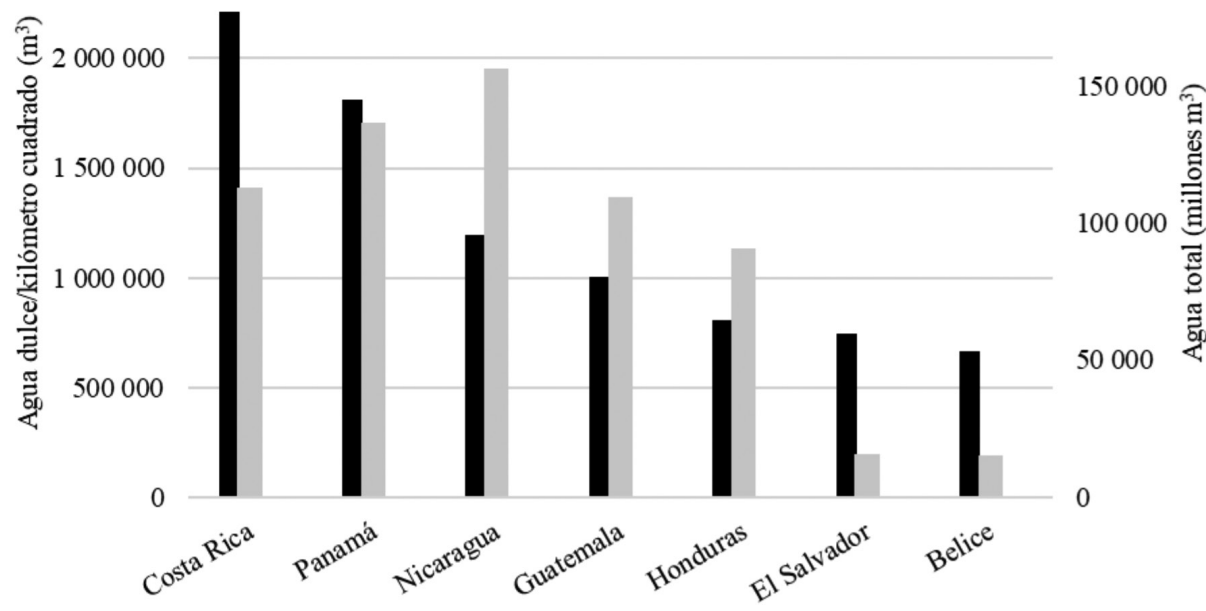

Fuente: Elaboración propia a partir de Banco Mundial (2018a).

Al comparar las cifras de agua dulce de la región, América Central cuenta con el $4.6 \%$ del agua de América Latina y el Caribe y con el $1.5 \%$ del mundo. Asimismo, la región latinoamericana posee el $32.4 \%$ del agua dulce del planeta (Banco Mundial, 2018a). Estas cifras no han variado con el tiempo, lo que sí ha variado según un informe de la Organización de las Naciones Unidas (2018) ha sido el deterioro de los ríos en América Latina, sobre todo desde los años noventa. Los países de América Central superan en más de tres veces el promedio por kilómetro cuadrado del mundo y más de cuatro veces el de América del Norte. Además, si bien esta región no es la más importante en cuanto a cantidad total de agua dulce, su atractivo va más por la eficiencia del territorio sobre todo en Costa Rica y Panamá.

Con la crisis ecológica y petrolífera, el agua se ha convertido en el recurso fundamental para el cambio de paradigma energético. Con los Programas de Ajuste Estructural (PAE) impuestos en la región, los Estados nacionales trasladaron gran parte de las responsabilidades que tenían sobre los recursos de uso común a los sectores privados (Barlow y Clarke) y la apertura de los mercados hidroeléctricos. Esto ha dado como resultado que conglomerados empresariales, entre ellos los centroamericanos, estén sumamente interesados en los hidronegocios. 
Al ser el agua un recurso vital, los hidronegocios han adoptado discursos "verdes" o "sustentables" para legitimar su accionar. En 1992 se celebró la Cumbre de la Tierra en Río, en la cual se dejó aún más claro el interés en que los sectores privados administren la naturaleza, ya que, según las pautas decididas en esta Cumbre, ${ }^{1}$ los recursos, al ser escasos, ya no deben estar al libre acceso de todos, sino solo de unos cuantos, es decir, de quienes paguen por acceder a ellos (Saxe y Delgado). Por esa misma línea del agua como un bien social, pero sobre todo económico, se dirigió la Conferencia de Dublín sobre el agua dos años antes (Declaración de Dublín sobre el Agua y el Desarrollo Sostenible), así como los Foros Mundiales de Agua realizados desde 1997 (Barlow, 2017).

Los organismos internacionales han estado a la vanguardia en este sentido. Barlow y Clarke afirman que los organismos internacionales como el Banco Interamericano de Desarrollo (BID), el Banco Mundial y el Fondo Monetario Internacional (FMI) han impulsado agresivas políticas para apertura de los hidronegocios en algunos países de América Latina y, para el caso específico de América Central, destacan los casos de El Salvador, Honduras, Nicaragua y Panamá (Figura 2). Las empresas interesadas en estos nichos comerciales son en su mayoría filiales de las tres corporaciones más poderosas del planeta en temas hídricos; se trata de las empresas francesas Suez y Vivendi y la alemana RWE-Thames Water (conocidas como el "Big-3").

Figura 2

FINANCIAMIENTO ACUMULADO DEL BANCO MUNDIAL Y EL BID EN ASUNTOS HÍDRICOS, SEGÚN PAÍS

2000

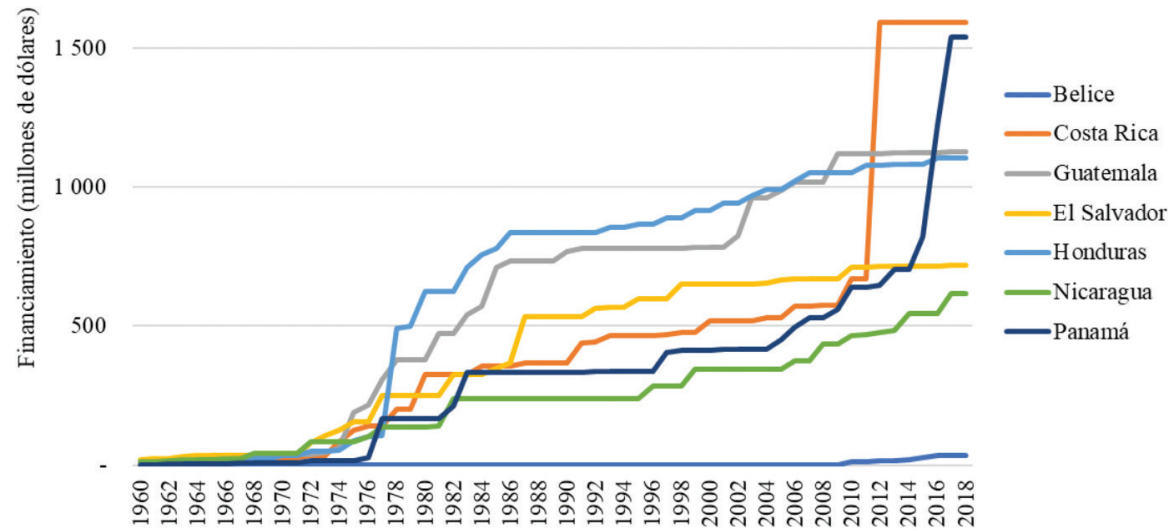

Fuente: Elaboración propia a partir de Banco Mundial (2018b) y el Banco Interamericano de Desarrollo. 
Las inversiones del BID son mucho mayores porque están dirigidas mayormente a temas de infraestructura (proyectos hidroeléctricos, abastecimiento y saneamiento y privatización de servicios hídricos), mientras que el Banco Mundial destina fondos principalmente a la conservación. La modernización de las legislaciones en temas hídricos ha llevado a ampliar la vía de la privatización y la exclusión del acceso al agua bajo el supuesto de "la tragedia de los comunes". La inversión de los organismos internacionales ha estado dirigida mayormente a los países que la Fundación Konrad Adenauer et al. (s. f.) considera que tienen mayores avances en las legislaciones hídricas, pero también a los dos países con mayor cantidad de agua por unidad de área.

Uno de los principales actores en ese sentido ha sido el Banco Mundial, que durante el gobierno de Ronald Reagan (1981-1989) tuvo a Barber Conable (1986-1991) como presidente de la institución. Conable, un conservador republicano neoyorquino, cuyo objetivo era dar un aire más "ambiental" al Banco, facilitó préstamos que impulsaran la protección de los recursos estratégicos (genes, agua, petróleo, entre otros). Detrás del Banco Mundial se encuentran figuras que representan los intereses de las principales corporaciones multinacionales, como el caso de Peter Brabeck-Letmathe, asesor del Banco en temas hídricos y gerente de Nestlé (Barlow, 2016). Por su parte, el BID en su rama infraestructural, en los años ochenta empezó a otorgar préstamos para lo que llama "adiestramiento del personal" en temas hidroeléctricos (Banco Interamericano de Desarrollo). De esta forma, asegura Gudynas, el propósito ha sido capitalizar y administrar la destrucción ecológica, sabiendo el valor de lo que se destruye.

Otro organismo de mucho peso en temas hídricos ha sido el Global Water Partnership (GWP), creado en 1996 como el brazo hídrico del Banco Mundial. Su interés en la custodia del agua proviene de las directrices acordadas en el Consenso de Washington y su estrategia se ha basado en la implementación, modificación y actualización de las leyes hídricas del planeta a través de la Gestión Integrada de los Recursos Hídricos (GIRH); un concepto creado en la Conferencia de Dublín de 1992. Más recientemente el Banco Mundial creó otro organismo durante el Foro Económico Mundial de 2008, conocido como 2030 Water Resources Group (WRG), integrado por representantes de multinacionales como Nestlé, Pepsi, Coca Cola, entre otras, para presionar políticas hídricas en los países convenientes a los mercados de agua (Hernández y Vázquez).

Shiva ha destacado que por un lado el modelo neoliberal ha tendido a la desregulación, pero al mismo tiempo estos organismos se han anclado a los Estados como operadores de sus intereses jurídicos. La Fundación Konrad Adenauer et al. (s. f.) visualiza que en temas hídricos América Central a ha quedado rezagada por la antigüedad de muchas leyes e incluso el no reconocimiento del derecho al agua a nivel constitucional (Escobar). Esta situación, afirma la Fundación Konrad Adenauer et al., (s. f.), dificulta la ejecución de proyectos, siendo Costa Rica, Panamá y Honduras los que más han avanzado en algunos aspectos. 


\section{El Corredor Biológico Mesoamericano y el biosaqueo}

En los años noventa se ratificaron dos planes regionales que marcarían el rumbo del "progreso" en América Latina: la Iniciativa para la Integración de la Infraestructura Regional Suramericana (IIRSA) y el Plan Puebla-Panamá (PPP) (ahora Proyecto Mesoamérica (PM)). Ambos proyectos se basan en la extracción de recursos y la industrialización, pero con poca popularidad. Ante eso, intentan ser legitimados por inversiones adyacentes para la "compensación" de los impactos ambientales, a lo cual se le conoce como lavado verde del extractivismo o greenwashing (Rodríguez Panqueva).

En esos años se gestaron las primeras ideas para el establecimiento de un corredor biológico en América Central. La idea fue aprobada en 1994 en Panamá para el establecimiento del Corredor Biológico Centroamericano, al cual le dieron el visto bueno la Universidad de Florida y el Proyecto Paseo Pantera; iniciado en 1990 como un acuerdo de cooperación de la Agencia de los Estados Unidos para el Desarrollo Internacional (USAID) (Rosas Hernández y Álvarez Icaza). Finalmente, el Corredor Biológico Mesoamericano (CBM) se fundó en 1997 (World Rainforest Movement, 2003). No obstante, como apunta Lungo y Baires, centró sus esfuerzos e intereses en los espacios casi prístinos y más ricos en recursos, pero no visualizó otros espacios como los urbanos o los ya degradados. Además, tuvo como objetivo la homologación de criterios para firmar la Declaración Conjunta Centroamericana-USA (CONCAUSA), que fue base del posterior TLC con Estados Unidos (Monge Hernández).

El CBM se deriva del PPP, financiado por el FMI, el Banco Mundial, el BID y la Unión Europea. Este corredor se extiende desde el sur de México hasta Panamá y ha sido criticado por su mediocre labor, pero también por su carácter hegemónico en la imposición de delimitaciones y ejecución de desalojos a nombre de la conservación. En 2008 pasó a formar parte de la Estrategia Mesoamericana de Sustentabilidad Ambiental (EMSA), coordinada principalmente por el PM (Estrategia Mesoamericana de Sustentabilidad Ambiental). La diversidad biológica y cultural de este espacio de 102 000000 de hectáreas posee relevancia geoeconómica y geopolítica, ya que conserva cerca el $7 \%$ de la biodiversidad mundial y abundantes reservas hídricas (Delgado Ramos, 2015).

Estas reservas hídricas tienen un enorme potencial energético y productivo (Prado Castro), sobre todo con el cambio de paradigma energético hacia la hidroelectricidad (Delgado Ramos, 2010). ${ }^{2}$ Es por esa razón que en 2001 se impulsó el Corredor Hidroeléctrico Mesoamericano (CHM) en las fuentes hídricas nacidas en el CBM (García Espinosa), para abastecer el Sistema de Interconexión Eléctrica de los Países de América Central (SIEPAC); una línea de transmisión eléctrica inaugurada en 2014, ratificada en 1998, pero planteada desde 1987, con una extensión de 1800 kilómetros. Posee sus orígenes con el PPP para el abastecimiento energético de los planes industriales en la región (Proyecto Mesoamérica). 
El CBM, como un espacio de custodia hídrica, se ha adaptado a los acuerdos mundiales Agenda 21 de 1992 de la Conferencia de Naciones Unidas sobre Medio Ambiente y Desarrollo (UNCED, por sus siglas en inglés), celebrada en Brasil, donde se promovieron dimensiones de cooperación internacional para acelerar el "desarrollo sostenible" de los "países en desarrollo" y políticas internas conexas, integración del ambiente en la adopción de decisiones, conservación de la diversidad biológica, aplicaciones de criterios para el aprovechamiento, ordenación y uso del agua dulce, recursos y mecanismos de financiación, entre otras (Organización de las Naciones Unidas). Además de eso, se estableció una directriz para desarrollar un programa (para todos los países) de sistemas nacionales integrados de contabilidad ambiental y económica (Banco Mundial, 2012).

A todo este proceso se sumaría el fallido Área de Libre Comercio de las Américas (ALCA), que daría lugar a las estrategias de los TLC segmentados, basados principalmente en los lineamientos de la privatización del Consenso de Washington. Con respecto a los TLC con Estados Unidos, para el caso específico de TLC de Estados Unidos con Centroamérica y República Dominicana, Ruiz Caro considera que de no haberse agregado a la lista de disconformes las excepciones a recursos como el agua y la energía, estos podrían ser apropiados por corporaciones extranjeras, debido a que hay un interés inicial por estos recursos.

Esto se debe a que al igual que con el Tratado de Libre Comercio de América del Norte (TLCAN), el país firmante no puede restringir el uso de recursos después de que se estableció su comercialización. Ruiz Caro asegura que es muy posible que algunas corporaciones interesadas en el agua hayan estado invirtiendo en la región a la espera de la consolidación de la liberalización del comercio de recursos como el agua. De hecho, Barlow y Clarke han advertido sobre el poderoso oligopolio formado por unas diez empresas, que para ese momento controlaban el 70 por ciento del mercado mundial del agua. De los países centroamericanos firmantes del TLC, solo Costa Rica estableció reservas para el suministro de agua y alcantarillado.

Si bien el CBM nace en momento histórico en que las preocupaciones ambientales son enormes, también surge en un momento de mercantilización de los bienes de la naturaleza y en el que los ciclos biogeoquímicos, la captura de carbono, la recarga acuífera y los códigos genéticos toman un valor de "servicio ecosistémico" que se compra y se vende (Bravo y Carrere), y debe ser custodiado para la defensa de la propiedad privada. En ese sentido, el CBM es un importante espacio para el resguardo de recursos como el agua ante su importancia como sustituto del petróleo y otros usos, como riego, embotellamiento y demás (Delgado Ramos, 2006; Delgado Ramos, 2015).

\section{La monetización de un derecho humano}

Las ciencias económicas han intentado desarrollar mecanismos de monetización que han sido sumamente debatidos durante décadas (Tortajada). Según la 
teoría económica respecto a los asuntos ambientales, las fallas del mercado se producen cuando no se cumplen las condiciones de un mercado competitivo, en especial las externalidades que limitan que el libre mercado no produzca el bienestar social óptimo, aunque sí maximiza los beneficios privados de sus acreedores. Estas externalidades (negativas) son efectos secundarios involuntarios que la producción o consumo de un agente generan sobre terceros de forma intertemporal, mientras que cuando estos efectos secundarios se dan de manera voluntaria por el incumplimiento de los compromisos se le conoce como riesgo moral (Moreno Sánchez).

En ese contexto las corporaciones asumen los impactos ambientales como factor de legitimación o de marketing, a lo cual se le denomina selección adversa, pero no necesariamente garantiza una compensación efectiva. A esto se suman los llamados incentivos perversos, que consisten en subsidios o beneficios que facilitan el extractivismo sin considerar la compensación de sus impactos. Esto adquiere dimensiones especiales con el agua, ya que es un recurso de uso común, es decir, que no es excluyente, pero es rival en su consumo (Moreno Sánchez). De este argumento se ha desprendido que el agotamiento de agua para consumo humano se haya dado por su alta demanda debido a su "libre acceso"; sin embargo, en Guatemala se ha demostrado que la administración local de la naturaleza es más efectiva que su privatización (Gibson, Lehoucq y Williams).

El carácter mercantil del agua tomó aún más fuerza con la creación de la Organización Mundial del Comercio (OMC) y la inserción de conceptos económicos para referirse a bienes de la naturaleza, como lo es el caso de los conceptos "capital natural" y "servicio ecosistémico", que como "servicio", se rige por el Acuerdo General sobre Aranceles Aduaneros y Comercio (AGCS), y que para el caso del agua se estima en USD 72 trillones anuales (Barlow, 2016). Esta organización ha sido sujeto de críticas porque a pesar de que no exige abiertamente a sus miembros la desregulación de los servicios hídricos, sí deja abierta la decisión de 1) mantener el servicio como un monopolio, público o privado; 2) abrir el servicio a los proveedores competidores, pero restringir el acceso a las empresas nacionales; o 3) abrir el servicio a los proveedores nacionales y extranjeros, pero sin que se establezcan compromisos del AGCS al respecto (Organización Mundial del Comercio).

Las opciones para los miembros de la OMC son limitadas, pero lo más importante de destacar es que estas no cambiaron tras la declaración de la ONU en 2010 sobre el Derecho Humano al Agua $^{3}$ y el pronunciamiento de algunas organizaciones al respecto. Además, a esto se suma que las corporaciones multinacionales, en conjunto con organismos internacionales operando en conjunto con los Estados subordinados, han estado especulando en Wall Street y tranzando a través del comercio electrónico, incluso antes de que se consolidaran los mercados de agua, como lo evidencia el trabajo de Barlow y Clarke. 
Barlow y Clarke sostienen que a medida que el modelo neoliberal avanza, incrementa no solo la pobreza y la desigualdad socioeconómica, sino también hídrica, al primar los derechos del agua a la agroindustria, que consume cerca del 70 por ciento del agua dulce utilizada en el planeta (Busby) y los hidronegocios en general que presionan en gran medida las reservas de agua subterráneas (Werner et al.), provocando nexos entre la situación climática, la disponibilidad hídrica y energética y los conflictos socioambientales y bélicos (CNA).

La inserción del agua en los mercados internacionales de capitales no es necesariamente para su conservación, sino más bien para su inversión a futuro desde el valor de opción, que es el precio de opción (disposición de pagar para conservar) menos el excedente del consumidor esperado, es decir, el excedente que el consumidor paga por haberse conservado ese recurso (Martínez Alier y Roca Jusmet). Tradicionalmente se ha utilizado la Regla de Hotelling para asignar valor monetario a los bienes de la naturaleza. Bajo esta lógica de competencia perfecta, la disminución en la oferta conlleva a un aumento en el precio. Martínez Alier y Roca Jusmet critican que la disminución en el stock no se da solamente por el agotamiento, sino también debido a que los proveedores restringen la oferta o la monopolizan.

La necesidad de resolver las falencias en la asignación de precios a la naturaleza ha llevado a que en los centros de enseñanza de todo el mundo se haya insertado la lógica de la mercantilización hídrica (Barlow, 2016). En 2012 fue constituido el SCAE como un marco conceptual que vincula la economía y el ambiente, mediante un método sistemático de organización de la información que permite cuantificar el stock de activos ambientales. Esto genera estadísticas que se relacionan con la economía en los centros de datos de los bancos centrales e institutos de estadísticas de cada país (Banco Mundial, 2012). Por su parte, la Organización para la Cooperación y el Desarrollo Económicos (OCDE) publicó sus principios de gobernanza del agua en el marco del sexto Foro Mundial del Agua, en conjunto con las principales corporaciones multinacionales hídricas en el mundo (Araral y Wang).

En cuanto a la implementación de las cuentas ambientales, México, Colombia y Costa Rica han sido los primeros países en realizarla en la década de los noventa con las directrices del Banco Mundial. Posteriormente, Guatemala se incorporó al proceso en 2006, siendo estos países los primeros en desarrollar el SCAE como estándar estadístico internacional para la contabilidad del "capital natural" y sus mediciones. A los países antes mencionados se le han sumado al proceso: Argentina, Brasil, Chile, Ecuador, Jamaica, Paraguay, Panamá, Perú, República Dominicana y Uruguay (Comisión Económica para América Latina).

Este marco central del SCAE involucró a países latinoamericanos que participaron en los comités de expertos (Brasil, Colombia y República Dominicana). Además, la Comisión Económica para América Latina (CEPAL) realizó revisiones al documento y conformó un comité editorial en el que participaron profesionales del Banco Central 
de Uruguay, del Instituto Nacional de Estadística y Geografía de México, la Universidad Rafael Landívar de Guatemala y el Departamento Administrativo Nacional de Estadística de Colombia. Sin embargo, en los créditos del documento de referencia del SCAE se aprecia que la mayoría de los colaboradores son provenientes del FMI, el Banco Mundial, la OCDE, la Unión Europea, entre otros (Banco Mundial, 2012).

El SCAE involucra conceptos de contabilidad de las normas y principios del Sistema de Cuentas Nacionales (SCN), que utilizan los bancos centrales y el FMI. Es así como se emplea el concepto de "flujo físico de insumos naturales, productos y residuos" para vincular la utilización económica del stock de insumos ambientales (recursos minerales, acuáticos y madereros) en el empleo de bienes y servicios producidos y consumidos por los hogares, industrias y gobierno. El SCN permite mostrar en unidades físicas y monetarias los recursos naturales (Banco Mundial, 2012). Las actividades económicas que se incluyen en la metodología para el cálculo del agua del SCAE son: agricultura, silvicultura, pesca, minas y canteras, industrias manufactureras, construcción, suministro de electricidad, gas, vapor, aire acondicionado, captación, tratamiento y distribución de agua, aguas servidas, gestión de residuos, actividades de recuperación y alcantarillado (Banco Mundial, 2012).

Dentro del objetivo de contar con cuentas de activos está la de comparar períodos contables, es decir, el registro del stock inicial y el final de activos ambientales, ya que con esto se logra estimar la tendencia y conocer los niveles de agotamiento o degradación. Como parte de los usos de dichas cuentas, se pueden desarrollar modelos econométricos que permitan realizar valoraciones de los recursos naturales y conocer sobre las expectativas para años venideros en cuanto la cantidad, precio y aporte a la riqueza de un país (desde la equivalencia en moneda), esto en su condición de bien económico (Romero Pérez; Silva Pinto y Cunha Marques).

La monetización de la naturaleza va más allá del registro de unidades físicas de los recursos, ya que se incluye el principio contable de revalorización de activos, lo que permite asignarle un valor a lo largo del tiempo y contemplar las variaciones de precio en un período determinado, en donde la oferta y la utilización del activo ambiental es la que registra las interacciones de las actividades económicas y el ambiente. No obstante, existen otras transacciones monetarias que se registran, tales como impuestos ambientales, rentas por extracción de recursos, subvenciones, donaciones y flujos de intereses (aumento de valor) (Banco Mundial, 2012).

Además, en relación con los precios de mercado y los flujos de ingresos esperado, como parte de los cálculos del SCAE, se incorpora el método de valor presente neto, el cual se sustenta en la medición del rendimiento futuro de los activos ambientales y la estimación de la vida útil del activo. Esto arroja una tasa de rendimiento conocida como Tasa Interna de Retorno (TIR) que es la que utilizan los inversionistas para determinar si invierten o no en alguna actividad (Banco Mundial, 2012). En ese sentido, Guatemala y Costa Rica, al incursionar en la creación y disponibilidad de 
estos datos, están apostando a la inversión empresarial en los hidronegocios (Banco Central de Costa Rica, 2013).

La oferta y utilización en unidades físicas del agua es calculada por medio de cinco secciones:

a) extracción de agua del ambiente; b) distribución y uso del agua extraída en empresas y hogares; c) flujos de agua residuales y reutilizadas (entre hogares y empresas); d) flujos de retorno de agua al ambiente; y e) evaporación, transpiración y agua incorporada en productos (Banco Mundial, 2012).

Estos elementos son fundamentales para entender la monetización del agua, ya que a través de esto se puede determinar la importancia para los hogares, empresas, gobiernos y en general para la economía (valor de uso y de cambio para la sociedad), así como el stock de insumos (la oferta) necesarios para determinar el precio e incorporarlos al SCN de los países.

Debido a los avances de los últimos treinta años en la estandarización de la contabilidad ambiental, se han desarrollado una serie de instrumentos de inversión relacionados con la biodiversidad, en donde están siendo transados en los mercados financieros internacionales. Evidencia de lo anterior, se puede observar cómo México, Argentina, Colombia y Costa Rica han incursionado en los Principios de Bonos Verdes (Green Bond Principles) del Banco Mundial, en donde las bolsas nacionales de valores de estos países ya están tranzando bonos cuyos fondos se destinan para financiar proyectos de energía renovable, agua, entre otros. Asimismo, se ha creado la Alianza Latinoamericana de Fondos de Agua, que analizaremos a continuación.

\section{Perspectivas sobre el acaparamiento hídrico en América Central: Evidencias recientes}

\section{Fondos Verdes: El caso de la Alianza Latinoamericana de Fondos de Agua}

La Alianza Latinoamericana de Fondos de Agua surgió en 2011 con la participación conjunta de The Nature Conservancy (TNC), la Fundación FEMSA, el BID y el Fondo Mundial para el Medio Ambiente (FMAM). Esta se describe a sí misma en su sitio web como un conjunto de "mecanismos de impacto colectivo que apuntan a contribuir a la seguridad hídrica de las áreas metropolitanas a través de la inversión en infraestructura natural". En el sitio web se explica, además, que la Alianza pretende contribuir al manejo de cuencas y a la gobernabilidad de los recursos hídricos.

Entre sus objetivos de acción destacan la atracción de recursos para la conservación de actores públicos y privados y la promoción de soluciones basadas en infraestructuras naturales, como complemento de las soluciones tradicionales de infraestructura. 
Además, también se plantea la instalación de redes de monitoreo para identificar impactos de dicha infraestructura natural en la mejora de la disponibilidad y calidad del agua (Alianza Latinoamericana de Fondos de Agua).

La Alianza cuenta con más de 120 organizaciones aliadas, tanto públicas-gubernamentales, como privadas y corporativas, provenientes de todo el mundo. Resulta pertinente prestar atención sobre el perfil de algunas de estas compañías (Figura 3).

Figura 3

PERFIL DE LOS PRINCIPALES ALIADOS DE LA ALIANZA LATINOAMERICANA

DE FONDOS DE AGUA

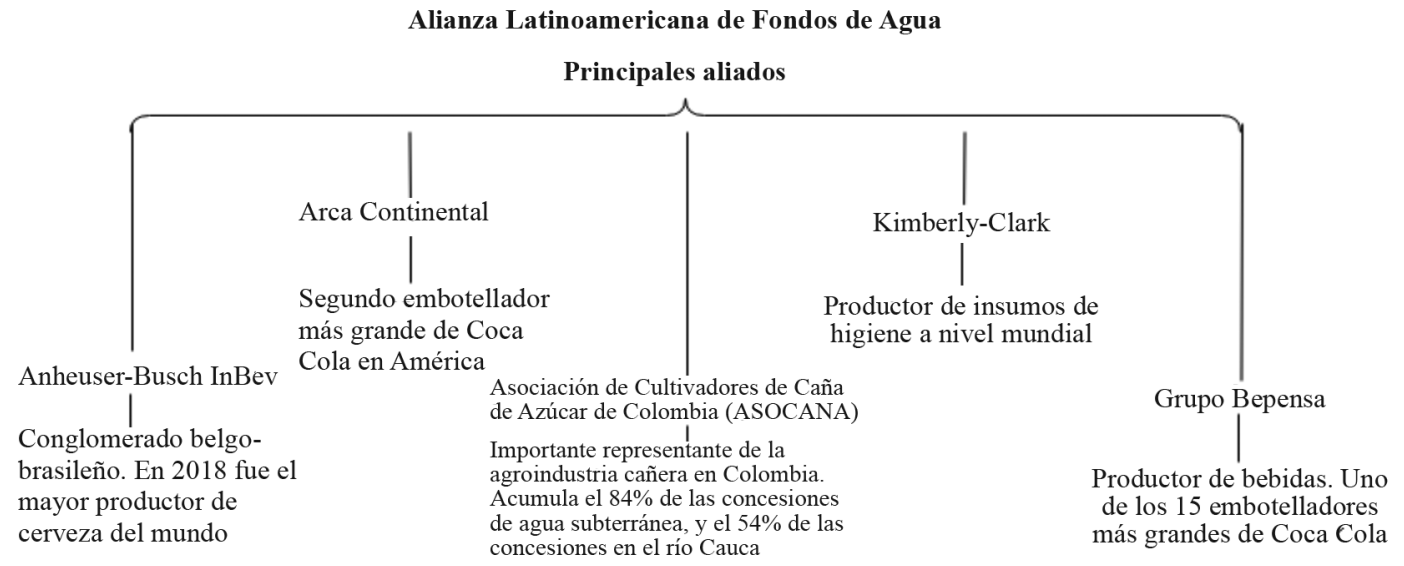

Fuente: Elaboración propia a partir de El Financiero; Pozzi; Arca Continental; Diario de Yucatán; Asocaña; Pérez, Peña y Álvarez.

La Alianza aglutina más de 19 Fondos de Agua, distribuidos en varios países latinoamericanos, entre ellos dos centroamericanos: Costa Rica y Guatemala. En el 2015 surgió Agua Tica como alianza público-privada, con un capital inicial de USD 200000 que fue aportado por la Alianza Latinoamericana de Fondos de Agua, en conjunto con Coca Cola-FEMSA, FIFCO, Fundación FEMSA, TNC, Fundación Costa Rica Estados Unidos para la Cooperación (CRUSA) y la Fundación para el Desarrollo de la Cordillera Volcánica Central (FUNDECOR). Estos fondos han sido manejados por el Banco Nacional, a través de un fideicomiso (Angulo). En diciembre de 2018 se concertó la primera Asamblea de Agua Tica, en la cual se conformó su junta directiva, en ese momento ocupó la presidencia Flora Montealegre, quien forma parte de la Fundación CRUSA (Revista Summa, 2018a).

En sus primeros años, Agua Tica ha enfocado su trabajo en la Gran Área Metropolitana, específicamente en las subcuencas del río Grande y río Virilla, que forman parte de la cuenca del río Grande de Tárcoles. Allí, el trabajo ha consistido en el establecimiento de un portafolio de inversiones, el cual 
se convierte en una herramienta útil para demostrar de manera técnico-científica dónde, cómo y cuándo invertir. De esta manera es más atractivo para los actores dentro del área de influencia que se sumen con inversiones directas que se van a traducir en un aumento en la calidad y cantidad de agua para sus procesos productivos (Guerrero et al., 2018).

Tomando como base tal priorización, Agua Tica ha puesto en marcha dos proyectos piloto. Uno de ellos se denomina "Agua por el Futuro", cuyo principal promotor es Coca Cola -a través de su embotelladora FEMSA- y su objetivo radica en "compensar la huella hídrica restante de los procesos de mitigación de huella por parte de la embotelladora con el fin de neutralizar su huella para el 2020" (Guerrero et al., 2018). El segundo proyecto se denomina "Modelo de retribución del servicio ambiental de recarga acuífera para la compensación de la huella hídrica de la empresa Florida Ice \& Farm" y se lleva a cabo en 10 fincas que abarcan 455 hectáreas de bosque bajo el esquema de protección de bosques de Fondo Nacional de Financiamiento Forestal (FONAFIFO).

En cuanto a Guatemala, la Fundación para la Conservación del Agua en la región Metropolitana de Guatemala (Funcagua) se estableció en 2017, con la participación de ocho grupos empresariales: Grupo Cayalá, Central America Bottling (CBC), Cementos Progreso, Cervecería Centro América, Corporación Multi Inversiones (CMI), Coca Cola-FEMSA, Grupo Pantaleón y TNC. Los socios se clasifican en tres categorías, según su aporte anual: plata, entre los USD 7000 y USD 14 999; oro, entre USD 15000 y USD 24 999; y platinum, por arriba de los USD 25000 (Funcagua, 2018). Cabe destacar que el ingeniero Héctor Leal, gerente general del Grupo Cayalá, figura además como presidente del consejo directivo de Funcagua (Revista Summa, 2018b).

La Fundación ha enfocado su accionar en 12 de los 17 municipios del Departamento de Guatemala, que conforman la región metropolitana, y contienen cerca del 94 por ciento de la población del país. Tal como se observa en la Memoria de Labores 2011-2017, de momento Funcagua se ha enfocado en el desarrollo de sistemas de información geográfica, herramientas estadísticas para la toma de decisiones, educación ambiental y acciones puntuales como limpieza de playas (Funcagua, 2017). Sin embargo, el Plan de Conservación del Agua de Funcagua (2018) muestra sus líneas de acción pretendidas, las cuales abarcan programas de protección y conservación forestal, sistemas agroforestales, etc.

Es importante atender que este tipo de procesos -brevemente reseñados anteriormente- se compaginan con el surgimiento de entes de apoyo técnico, algunos de ellos de carácter transnacional y ampliamente conocidos, tales como World Wildlife Fund (WWF), Conservation International (CI), TNC, etc., y otros de origen costarricense como lo fue el Instituto Nacional de Biodiversidad (INBio) -cuya labor consultora se desarrolló en otros países- (Rodríguez Cervantes); y más recientemente el caso de la Asociación Costa Rica por Siempre, con una visión mucho más empresarial que la que 
tuvo el INBio. Este fenómeno parece ser mucho más evidente en Costa Rica por haber apostado por la industria de la conservación de manera más fuerte.

Esta asociación fue constituida en el 2009, su finalidad es la de administrar la iniciativa de conservación en conjunto con el Gobierno de Costa Rica, TNC, Gordon \& Betty Moore Foundation y Linden Trust for Conservation. Esto se ha dado mediante un sistema de áreas protegidas (terrestres, marinas y de agua dulce) y la figura de fideicomiso de Canje de Deuda por Naturaleza. Estos recursos se invierten en seis áreas geográficas en el país: Osa, La Amistad, Tortuguero, Maquenque, área noroeste del Rincón de la Vieja y Nicoya. Al 2018, las inversiones reflejadas en los estados financieros de la asociación son por un valor de mercado de USD 61472 076, los fondos se mantienen bajo la custodia del Banco BCT. Además, recibió donaciones por USD 6654100 (Asociación Costa Rica por Siempre, 2018a; Asociación Costa Rica por Siempre, 2018b).

La Figura 4 muestra, por un lado, la rotación de los puestos directivos de esta asociación y, por el otro, la presencia de personas vinculadas al ámbito empresarial. Por ejemplo, vemos figuras como la de Javier Chávez, propietario de Grupo Bursátil Aldesa (primer puesto de bolsa en Costa Rica) y cuya esposa es Edna Camacho, quien ha participado como miembro de la junta directiva de FIFCO desde el 2005 y hasta el 2018 (Florida Ice \& Farm Co., 2018b) y es exministra de Coordinación Económica del Gobierno de Costa Rica. También Thomas Alvarado quien fungió como gerente financiero de esta última empresa entre 1997 y el 2015 y es el actual presidente de la Bolsa Nacional de Valores (Bolsa Nacional de Valores). 


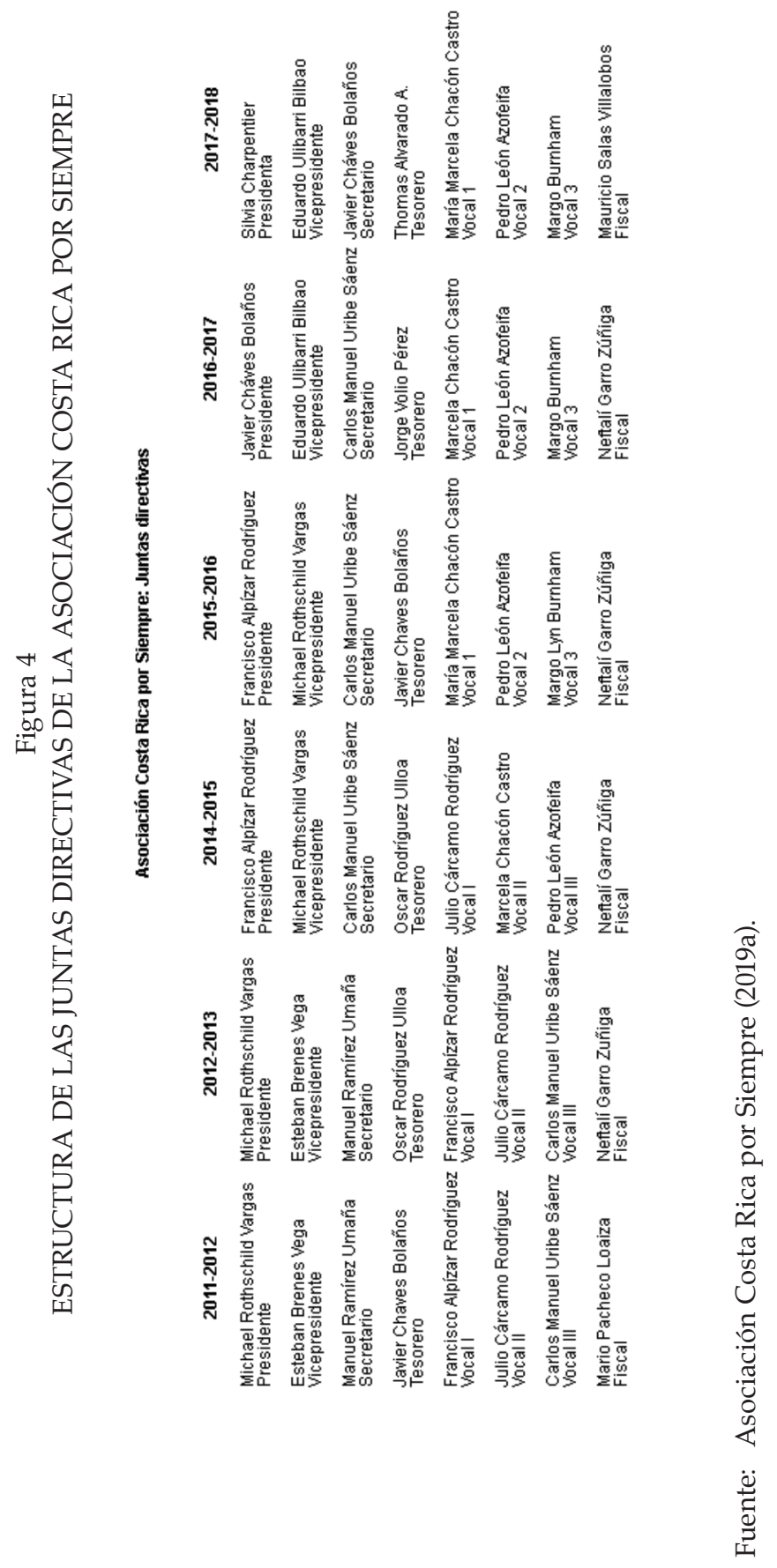


Además, el empresario Carlos Manuel Uribe Sáenz quien es miembro de la junta directiva y accionista de Grupo Cuestamoras. Por su parte, Eduardo Ulibarri Bilbao ha tenido ligámenes con Grupo Nación y Grupo Bursátil Aldesa, mientras que Jorge Volio Pérez es un banquero de inversión, propietario de Volio Capital y hermano del empresario y político Alfredo Volio Pérez (Asociación Costa Rica por Siempre, 2019a; Asociación Costa Rica por Siempre, 2019b; Aldesa; Cuestamoras, 2019).

\section{Estrategia de diversificación de los GED: La creación de valor compartido y los recursos naturales}

Durante el transcurso del siglo XXI las nuevas opciones de inversión para los GED han tenido una línea temática en torno a los recursos naturales y la Responsabilidad Social Corporativa (RSC). Como se mencionó anteriormente, el 2012 fue un año importante para la consolidación metodológica y técnica de la monetización ambiental, lo cual ha venido de la mano con una serie de planteamientos académicos e ideológicos dirigidos a grupos empresariales sobre la creación de teorías y conceptos como el valor compartido y el capitalismo consciente, respectivamente, como forma de reinvención frente a los tratados bilaterales y multilaterales (Robles Rivera).

Para el caso del valor compartido, este concepto fue acuñado por Michael E. Porter y Mark R. Kramer y publicado por la revista Harvard Business Review. El planteamiento de estos profesores universitarios y asesores empresariales gira en torno a la reinvención del capitalismo, ya que este está bajo "asedio" por la pérdida de confianza en las empresas y que "las necesidades de la sociedad, y no solo las necesidades económicas convencionales, son las que definen los mercados, y los males de la sociedad pueden crear costos internos para las empresas" (Porter y Kramer 5). Además, estos autores definen el valor compartido como las prácticas operativas que buscan la eficiencia empresarial al mismo tiempo que "ayudan a mejorar" las condiciones socioeconómicas de las localidades donde funcionan.

Para lograr la creación de valor compartido, las empresas deben mejorar su productividad en el uso de energía, impacto ambiental, habilidad, salud y seguridad de los empleados y el uso del agua. Además, se afirma que esta debe reemplazar a las estrategias de RSC, ya que estas últimas se han centrado principalmente en la reputación de las marcas y tienen poca incidencia en las problemáticas sociales (Porter y Kramer).

El caso del capitalismo consciente va por la misma línea de la reinvención del capitalismo a través de la legitimación de consignas ideológicas como la de darle un "rostro más humano", para de esa forma "elevar el valor de lo humano en los negocios para crear prosperidad, plenitud y compromiso en el sector privado". Se basa en cuatro pilares: 1) propósito superior, 2) orientación hacia públicos de interés,

3) cultura consciente y 4) liderazgo consciente. Esta tendencia reciente no se plantea 
una reinvención desde la política empresarial, sino que más bien deja a voluntad de las personas empresarias aplicar estos principios (Capitalismo Consciente).

Uno de los sectores de inversión más prometedores para los grupos empresariales ha sido el energético, impulsado en Costa Rica con la Ley N. 7200 y su reforma. Además, la Ley N. 7508 , durante los años noventa, le garantizó a los inversores hidroeléctricos que un 15 por ciento de la energía del país sería generada por proyectos privados, beneficiando a las familias de los políticos que precisamente impulsaron esta apertura, como lo son las familias Figueres Olsen, Figueres Boggs, Koberg Gutiérrez, Koberg Facio, Gurdián Montealegre, Gurdián Moreno, Corrales Villalobos, Arias Sánchez, Sánchez Benavides, Sánchez Marí, Matamoros Corrales, Madrigal Matamoros y Ramírez Steller (Álvarez Mora).

Este proceso se dio en Guatemala a través de la aprobación del Decreto Legislativo N. 9 93-96, Ley General de Electricidad, bajo la presidencia de Álvaro Arzú Irigoyen (1996-2000). A partir de allí, se vendió al capital extranjero gran parte de las dos empresas públicas dedicadas a la generación eléctrica: Instituto Nacional de Electrificación (INDE) y la Empresa Eléctrica de Guatemala (EEGSA). La promulgación de esta ley contó con el beneplácito y seguimiento cercano del sector empresarial guatemalteco. Algunos de los pioneros del negocio hidroeléctrico guatemalteco fueron parte de la Comisión Asesora del Sector Privado, de cara a promulgación de la Ley General de Electricidad, por ejemplo, el multimillonario Juan Luis Bosch Gutiérrez, copresidente de CMI (Rodríguez Carmona y De Luis).

\section{Las élites y la inversión en agua}

Analizamos cuatro grupos empresariales que cuentan con inversiones en la región centroamericana y que desde hace varios años han iniciado una serie de diversificaciones de negocios hacia la creación de valor compartido y aprovechamiento de la monetización ambiental, como parte de las promisorias inversiones del futuro (Figura 5).

El primer caso es el de Grupo Cuestamoras. Este es un conglomerado de empresas dirigido por la familia Uribe, cuyos negocios se remontan desde mediados del siglo XX con la Corporación de Supermercados Unidos, que fue vendido paulatinamente desde el 2005 a Walmart (INCAE). Este grupo tiene dos divisiones de negocios relacionadas con la explotación de recursos naturales, una de energía y otra de bosques, en donde, según su memoria anual (Cuestamoras, 2017) podemos encontrar que:

- Es el cuarto exportador de energía más grande en el Mercado Eléctrico Regional.

- Cuenta con inversiones en bosques con 3500 hectáreas de fincas en Costa Rica.

- Posee certificaciones de Carbono Neutralidad y de Empresa B.

- Tiene un programa activo de medición de la biodiversidad en sus fincas. 
El Grupo Cuestamoras también liga sus inversiones inmobiliarias a su división de negocios de bosques. Esto se puede visualizar con el reciente proyecto del centro comercial Oxígeno Human Playground, que estableció el convenio Liberando Oxígeno. Esto compromete al centro comercial a mitigar las emisiones de Gases de Efecto Invernadero (GEI) que se generaron durante su construcción, las cuales serían compensadas mediante la conservación en Cutris de Alajuela, Río Banano y Zent, que son parte de la unidad Cuestamoras Bosques (Canales).

Por su parte, se encuentra Florida Ice \& Farm, cuya historia empresarial se remonta a 1908 con la producción y comercialización de cervezas, licores, bebidas y alimentos. Desde el 2001 invierte en la protección de cuencas hidrográficas y además ha desarrollado inversiones "verdes". En sus estados financieros de 2018 se observa que tienen inversiones por aproximadamente USD 51000000 (37.39\% del capital accionario) en la empresa Inversiones Cerveceras Centroamericanas, la cual posee la Central Hidroeléctrica el Salto Y-Y en Nicaragua (Deloitte). También, en el 2009 oficializó la creación del Refugio Nacional de Vida Silvestre Mixto Conchal con 40 hectáreas de bosque seco y manglar. Asimismo, mantiene Pagos de Servicios Ambientales (PSA) del FONAFIFO en la Cuenca Alta del Barva en el Valle Central (650 hectáreas) y en el Parque Vivo en la Península de Osa (150 hectáreas) (Florida Ice \& Farm Co., 2018a).

Para el caso de Guatemala, se encuentra la Corporación Multi-Inversiones, con más de 90 años de historia, siete unidades de negocio en 14 países y más de 45 mil colaboradores. Cuenta con una capacidad instalada para la generación eléctrica de 741 MW en Centroamérica con un proyecto activo llamado Agua Buena para la protección de cuencas hidrográficas, además, utilizan su Fundación Juan Bautista Gutiérrez para sus programas de RSC (Corporación Multi-Inversiones). También las inversiones están presentes en el área de bosques, ya que poseen la Reserva Natural de Renace con 46 hectáreas, en la cual realizan monitoreos e inventarios de unas 140 especies de flora y 96 especies de fauna.

Finalmente, se incorporó el grupo empresarial Corporación Castillo Hermanos, cuyos inicios se remontan a la época colonial (Bull y Kasahara), el cual tiene en su haber más de 90 empresas en los sectores de bienes raíces, alimentos y bebidas, sector agropecuario, turismo, transporte, comercio y banca. A pesar de la limitada información sobre este grupo, sus inversiones "verdes" no quedan fuera de su portafolio de negocios, ya que posee más de 30 hectáreas de bosques para el cuido y reforestación. Asimismo, todos sus proyectos sociales los canaliza a través de su Fundación Castillo Córdova (Revista Summa, 2015; Fundación Castillo Córdova). 
Figura 5

PANORAMA DE LOS HIDRONEGOCIOS EN AMÉRICA CENTRAL

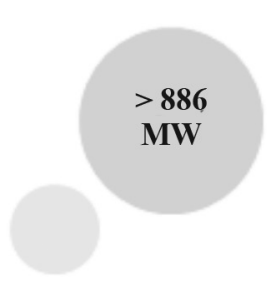

Energía

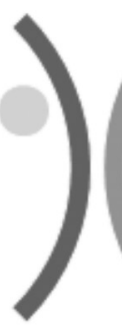

.

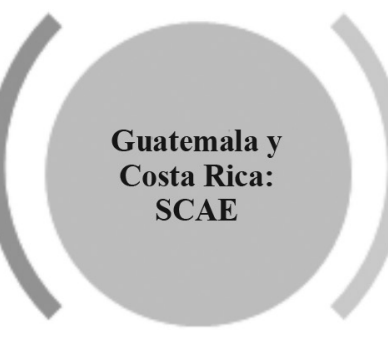

Agua

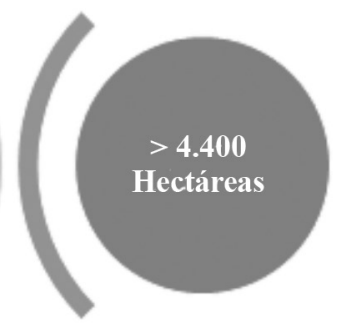

Bosques

Fuente: Comisión Económica para América Latina (2017), Corporación Multi-Inversiones (2019), Cuestamoras (2017) y Florida Ice \& Farm (2018a).

Las inversiones en bosques y energía permiten tener acceso al recurso hídrico, esto bajo un contexto en que el agua cada vez escasea más y su uso es menos accesible para las poblaciones. Parte fundamental en las decisiones financieras para invertir es tener la seguridad jurídica y garantizar su demanda, para este caso la metodología de monetización y la importancia del agua para los seres humanos son pilares para especular sobre rendimientos futuros que le den valor a sus inversiones, sin olvidar que las premisas detrás de estos negocios son las de generar valor compartido y darle mayor "conciencia" al capitalismo, tal y como se mencionó anteriormente.

\section{Conclusiones y aperturas}

Los organismos internacionales han cumplido un desempeño central en la monetización del agua y de otros bienes de la naturaleza, a través de apoyo financiero y ajustes estructurales que crean condiciones óptimas para la diversificación de las inversiones y la exploración en nuevos nichos económicos. Esto se ha dado con mayor facilidad con la inserción de conceptos de economía para su uso en la biología y en la academia en general, como lo es el caso del concepto "servicio ecosistémico" o -aún más claro- con el concepto de "capital natural" (Barlow, 2016).

El agua se posiciona bajo una escasez acelerada que se materializa en una menor oferta de este, lo cual ha generado procesos de acaparamiento por la expectativa de su precio futuro. Esto es un pilar medular de la monetización, del cual tienen gran participación los entes encargados de mediar en estos procesos de greenwashing y de acaparamiento del derecho al uso de agua. Lo anterior implica que, aunque no sea una privatización del agua como tal, un proceso sumamente deslegitimado por sus fallidos intentos en países como España, Hungría, Argentina y el simbólico caso de Bolivia 
(Cochabamba) a finales de los años noventa (Barlow y Clarke), de igual manera niega su acceso a quienes no tienen la capacidad de compra, y viola el derecho humano de acceso al agua.

Esto posiciona en el debate la contradicción de la visión del agua como un bien económico o como un derecho humano. Es claro que la primera no es una solución en tanto existe evidencia empírica de que incluso la administración local ha sido más efectiva en la conservación de la naturaleza en su generalidad. La segunda, a pesar de ser aprobada de manera casi universal, se ve condicionada a la primera, debido a los silenciosos avances en la monetización de parte de pequeños y poderosos grupos como un argumento de conservación del recurso. En ese sentido, la imposición de los mercados de agua vulnera el derecho humano de acceso al agua en tanto que su escasez aumenta el precio y reduce su asequibilidad, así como también su accesibilidad y su cantidad suficiente para garantizar la dignidad.

Por lo tanto, ofrecemos algunas propuestas que enriquezcan el conocimiento al respecto. Una de ellas es ampliar la información sobre las situaciones y conflictos hídricos en la región. También es importante profundizar en la comprensión de los mecanismos técnicos de monetización. Por último, es fundamental ampliar el análisis de las redes de poder e inversiones de otros GED en la región centroamericana y latinoamericana en temas hídricos, lo cual facilite sobre todo a los movimientos sociales en defensa del derecho humano al agua la presión para la toma de decisiones en función de que la mayor cantidad de seres vivos puedan acceder a este líquido vital.

\section{Notas}

1 En esta Cumbre se acordó la Declaración de Principios para el Manejo Sustentable de Bosques, la cual indica que es responsabilidad de los Estados proteger los bosques, pero también es de soberanía de estos el uso, manejo y el ordenamiento en función de sus intereses de desarrollo y los de la economía de libre mercado (World Rainforest Movement, 1992). También se acordó el Convenio sobre la Diversidad Biológica (CDB), que consolidó la agenda de derechos de propiedad intelectual y la privatización de los recursos genéticos y los conocimientos tradicionales (Saxe y Delgado).

2 Los países con mayor Densidad de Potencial Hidroeléctrico $\left(\mathrm{KW} / \mathrm{km}^{2}\right)$ en América Latina son -de mayor a menor- Costa Rica, El Salvador, Ecuador, Venezuela y Perú (Alarcón Rodríguez).

3 La Declaración indica que el derecho humano al agua y al saneamiento debe ser suficiente y continuo para el uso personal y doméstico, debe ser saludable, aceptable en su aspecto, físicamente accesible a menos de un kilómetro y menos de 30 minutos, y asequible, con un valor no superior a un 3 por ciento de los ingresos del hogar (United Nations Water).

\section{Agradecimientos}

A Maude Barlow (Council of Canadians) por sus valiosos aportes y la recomendación de fuentes. 


\section{Bibliografía}

Alarcón Rodríguez, Arturo Daniel. El Sector hidroeléctrico en Latinoamérica: Desarrollo, potencial y perspectivas. Washington DC: BID, 2018. DOI:_10.18235/0001149

Aldesa. Eduardo Ulibarri Bilbao. Aldesa, 2019. Recuperado de https://bit.ly/2WDG1Jq

Alianza Latinoamericana de Fondos de Agua. ¿Qué es la Alianza Latinoamericana de Fondos de Agua? Alianza Latinoamericana de Fondos de Agua, 2018. Recuperado de https:// bit.ly/2FDQJGy

Álvarez Mora, M. Un negocio que mata: leyes 7200 y 7508. San José: Degeneración Eléctrica. Campaña por la Derogatoria de las Leyes 7200 y 7508, 2003.

Angulo, Y. (29 de octubre de 2015). "Agua Tica" se convierte en el primer fondo para custodiar el patrimonio hídrico del país. El Mundo. Recuperado de https://bit.ly/2XLsPIV

Arca Continental. Informe anual 2017. Monterrey: Arca Continental, 2017.

Araral, E. y Wang, Y. Water Governance 2.0: A Review and Second Generation Research Agenda. Water Resour. Manage., 27, 11(2013): 3945-3957. DOI: 10.1007/s11269-013-0389-x

Asociación Costa Rica por Siempre. Fideicomiso de Inversión y Administración de Fondos para la Ejecución del Acuerdo de Conservación de Bosques-Primer Canje de Deuda (Entidad Costarricense). Estados Financieros 30 de setiembre de 2018 y 2017 Conjuntamente con el Informe de los Auditores Independientes. San José: Asociación Costa Rica por Siempre, 2018a.

Asociación Costa Rica por Siempre. Fideicomiso Segundo Canje de Deuda por Naturaleza (Entidad Costarricense) Estados Financieros 30 de setiembre de 2018 y 2017 Conjuntamente con el Informe de los Auditores Independientes. San José: Asociación Costa Rica por Siempre, 2018b.

Asociación Costa Rica por Siempre. Jorge Alberto Volio Pérez. Asociación Costa Rica por Siempre, 2019a. Recuperado de https://bit.ly/2Vkidha

Asociación Costa Rica por Siempre. Eduardo Ulibarri Bilbao. Asociación Costa Rica por Siempre, 2019b. Recuperado de https://bit.ly/2PRkgn3

Asocaña. Fondo agua por la vida y la sostenibilidad. Asocaña, 2016. Recuperado de https://bit. ly/2GCKm9c

Banco Mundial. Banco de datos estadísticos. Banco Mundial, 2018a. Recuperado de https://bit. ly/2uBHvYp

Banco Mundial. Proyectos y operaciones. Banco Mundial, 2018b. Recuperado de https://bit. ly/2UkjN1b

Banco Mundial. Sistema de Contabilidad Ambiental y Económica. Nueva York: Grupo Banco Mundial, 2012.

Barlow, M. y Clarke, T. Oro azul. Las multinacionales y el robo organizado de agua en el mundo. Madrid: Paidós, 2004.

Barlow, M. Boiling Point: Government Neglect, Corporate Abuse, and Canada's Water Crisis. Toronto: ECW Press, 2016.

Barlow, M. Water for Sale How Free Trade and Investment Agreements Threaten Environmental Protection of Water and Promote the Commodification of the World's Water. Ottawa: Council of Canadians, 2017.

Banco Central de Costa Rica. Primeros resultados de las Cuentas Ambientales de Costa Rica. Banco Central de Costa Rica, 2013. Recuperado de https://bit.ly/30eWpSM

Banco Interamericano de Desarrollo. Proyectos del BID. BID, 2019. Recuperado de https://bit. ly/2DbTCQ2 
Bolsa Nacional de Valores. Thomas F. Alvarado Acosta. Bolsa Nacional de Valores, 2019. Recuperado de https://bit.ly/2vMeAkU

Bravo, E. y Carrere, R. Áreas protegidas ¿Protegidas contra quién? Montevideo: Oilwatch y Movimiento Mundial por los Bosques Tropicales, 2004.

Bull, B. y Kasahara, Y. La transnacionalización de los grupos empresariales diversificado y el rostro cambiante de las élites económicas centroamericanas. Anuario de Estudios Centroamericanos, 43, (2017): 37-69. DOI: 10.15517/aeca.v43i0.31549

Busby, J. Water and U.S. National Security. New York: Council on Foreign Relations, 2017.

Cambridge University. Diccionario inglés, monetize. Cambridge University, 2018. Recuperado de https://bit.ly/2uCGkYO

Canales, D. Empresa costarricense incursiona en el mercado inmobiliario como desarrollador y operador con sus dos primeros proyectos: Oxígeno y Santa Verde. Versión Inmobiliaria, 2019. Recuperado de https://bit.ly/2VcVFdF

Capitalismo Consciente. Capítulo Costa Rica. Capitalismo Consciente, 2019. Recuperado de https://bit.ly/2VmX4mv

Comisión Económica para América Latina. Avances y desafíos de las cuentas económico-ambientales en América Latina y el Caribe. Santiago: ONU, 2017.

Corporación Multi-Inversiones. CMI Energía. CMI, 2019. Recuperado de https://bit.ly/2V7LwPk

CNA. The Role of Water Stress in Instability and Conflict. Washington DC: CNA, 2017.

Cuestamoras. Memoria anual 2017. San José: Cuestamoras, 2017.

Cuestamoras. Carlos Manuel Uribe. Cuestamoras, 2019 Recuperado de https://bit.ly/2H84dyq

Declaración de Dublín sobre el Agua y el Desarrollo Sostenible, 1992. Recuperado de http://bit. ly/2LOLad4

Declaración de Rio sobre el Medio Ambiente y el Desarrollo, 1992. Recuperado de https://bit. ly/2Y9D8kd

Delgado Montoya, É. (12 de febrero de 2010). Alfredo Volio asume como presidente del Banco Nacional. El Financiero. Recuperado de https://bit.ly/2J7hR7d

Delgado Ramos, G. C. Cambio de paradigma energético y las nuevas tecnologías. Temas de Nuestra América, 26, 49(2010): 29-48.

Delgado Ramos, G. C. Agua: Usos y abusos. La hidroelectricidad en Mesoamérica. México DF: CEIICH-UNAM, 2006.

Delgado Ramos, G. C. Biodiversidad, desarrollo sustentable y militarización: Esquemas del saqueo en Mesoamérica. México DF: CEIICH-UNAM, 2015.

Deloitte. Estados financieros consolidados-Informe de los auditores independientes. Deloitte, 2018. Recuperado de https:// bit.ly/2J5WpiT

Diario de Yucatán. (12 de octubre de 2012). Consorcio de empresas. Recuperado de https://bit. ly/2PATWxb

El Financiero. (3 de agosto de 2018) Heineken quiere 'brindar' en China y comprará participación en mayor cervecera. Recuperado de https://bit.ly/2Wa1Z6H

Estrategia Mesoamericana de Sustentabilidad Ambiental. Corredor Biológico Mesoamericano. EMSA, 2018. Recuperado de https://bit.ly/2PqTIYo

Escobar, G. Derecho al agua. XII informe sobre Derechos Humanos. Madrid: Trama Editorial, 2015.

Florida Ice \& Farm Co. Asamblea General Ordinaria y Extraordinaria de Accionistas de Florida Ice and Farm Company, S.A. FIFCO, 2018a. Recuperado de https://bit.ly/2JpOvA8

Florida Ice \& Farm Co. Comunicado de hecho relevante. FIFCO, 2018b. Recuperado de_https://bit. ly/2J6eehZ 
Fundación Castillo Córdova. Nuestro trabajo. Fundación Castillo Córdova, 2019. Recuperado de https://bit.ly/2VQz4aS

Fundación Konrad Adenauer, Asociación Empresarial para el Desarrollo y United Way. Comparación de legislación ambiental centroamericana. Análisis de la rigurosidad de la legislación en países centroamericanos para controlar la gestión ambiental de las empresas. San José: Alianza Empresarial para el Desarrollo.

Funcagua. Fondo de Agua en la Región Metropolitana de Guatemala. Funcagua, 2017. Recuperado de https://bit.ly/2J11TKW

Funcagua. Memoria de Labores: inicios de la FUNCAGUA (2011-2017). Funcagua, 2017. Recuperado de https://bit.ly/2KtkJJU

Funcagua. Plan de Conservación del Agua. Funcagua, 2018. Recuperado de https://bit. $\mathrm{ly} / 2 \mathrm{KkgW} 2 \mathrm{Q}$

García Espinosa, C. El corredor hidroeléctrico mesoamericano contra el patrimonio hidráulico de los pueblos originarios de México y Centroamérica. Boletin de Antropología, 31, 52(2016): 109-128. DOI: 10.17533/udea.boan.v31n52a09

Gibson, C., Lehoucq, F. y Williams, J. Does Privatization Protect Natural Resources? Property Rights and Forests in Guatemala. Social Science Quarterly, 83, 1(2002): 206-225. DOI: 10.1111/1540-6237.00079

Gudynas, E. La ecología política de la crisis global y los límites del capitalismo benévolo. Íconos. Revista de Ciencias Sociales, 36, (2010): 53-67.

Global Water Partnership. La situación de los recursos hídricos en Centroamérica. Hacia una gestión integrada. Washington DC: GWP, 2017.

Guerrero, M., Carazo, F. y Herrera-Fernández, B. Agua Tica: una alianza público-privada para la conservación del recurso hídrico. Ambientico, 268, (2018): 25-30.

Hernández, A. y Vázquez, C. (Eds.). Atlas de la agroindustria. Datos y hechos sobre la industria agrícola y de alimentos. México DF: Fundación Heinrich Böll y Fundación Rosa Luxemburg, 2019.

INCAE. Caso vivo Cuestamoras. INCAE, 2017. Recuperado de https://bit.ly/2H4MTZX

Investopedia. Diccionario financiero, monetize. Investopedia, 2018. Recuperado de https://bit. ly/2El5EKu

Lungo, M. y Baires, S. La Alianza Centroamericana para el Desarrollo Sostenible y la gobernabilidad de las ciudades centroamericanas. Gobernabilidad urbana en Centroamérica. Lungo, M. (Comp.). San José: FLACSO, 1998.

Martínez Alier, J. y Roca Jusmet, J. Economía ecológica y política ambiental. México DF: Fondo de Cultura Económica, 2001.

Monge Hernández, C. Desarrollo sostenible a la tica: geopolítica y ambiente en la Administración Figueres Olsen (1994-1998). Revista Rupturas, 5, 1(2015): 1-21. DOI: 10.22458/rr.v5i1.712

Moreno Sánchez, R. del P. Incentivos económicos para la conservación. Un marco conceptual. Washington DC: USAID, 2012.

Organización Mundial del Comercio. La OMC no trata de quedarse con su agua. OMC, 2018. Recuperado de https://bit.ly/2LMcreE

Organización de las Naciones Unidas. Programa 21. Río Janeiro: Sistema de Naciones Unidas, 1992.

Organización de las Naciones Unidas. Soluciones basadas en la naturaleza para la gestión del agua. Nueva York: ONU, 2018. 
Oxford University. Diccionario inglés, monetize. Oxford University, 2018. Recuperado de https:// bit.ly/2uDQyYI

Pérez, M. A, Peña, M. R. y Álvarez, P. Agro-industria cañera y el uso del agua. Análisis crítico en el contexto de la política de agrocombustibles en Colombia. Ambiente y Sociedades, 14, 2, 2011: 153-178.

Porter, M. y Kramer, M. La creación de valor compartido: cómo reinventar el capitalismo y liberar una oleada de innovación y crecimiento. Harvard Business Review, 89, 2(2011): 31-49.

Pozzi, S. (13 de octubre de 2015). AB Inbev e SABMiller controlarão um terço das vendas de cerveja. El País. Recuperado de https://bit.ly/2XRIeBu

Prado Castro, M. El Corredor Biológico Mesoamericano. Estrategia de desarrollo para Centroamérica. San José: Lara Segura y Asociados Editores, 2004.

Proyecto Mesoamérica. Acerca del PM. Proyecto Mesoamérica, 2018. Recuperado de https:// bit.ly/2Lpopez

Revista Summa. (4 de noviembre de 2015). Guatemala: United Way Latinoamérica otorga mención honorífica a Corporación Castillo Hermanos. Recuperado de https://bit. ly/2vJaR7M

Revista Summa. (7 de diciembre de 2018a). Nombran junta directiva que dirigirá el trabajo en Agua Tica. Recuperado de https://bit.ly/2UELs9h

Revista Summa. (20 de abril de 2018b). Funcagua consolida alianzas por la seguridad hídrica de Guatemala. Recuperado de https://bit.ly/2Gybl5H

Robles Rivera, F. Los de entonces ya no son los mismos. Acumulación por desposesión en la última década en El Salvador y Costa Rica. Anuario de Estudios Centroamericanos, 37, (2011): 105-137.

Rodríguez Carmona, A. y De Luis, E. Hidroeléctricas insaciables en Guatemala. Madrid: Asociación Paz con Dignidad, 2016.

Rodríguez Cervantes, S. El despojo de la riqueza biológica: de matrimonio de la humanidad a recurso bajo soberanía del Estado. México DF: Itaca, 2012.

Rodríguez Panqueva, D. Capitalismo verde. una mirada a la estrategia del BID en cambio climático. Bogotá: CENSAT Agua Viva, 2012.

Romero Pérez, J. E. El agua como bien económico. Revista de Ciencias Jurídicas, 113, (2007): 1-35.

Rosas Hernández, M. I. y Álvarez Icaza, P. El Corredor Biológico Mesoamericano: Cooperación regional para el desarrollo social incluyente. Proyecto Mesoamérica. Cuadernos mesoamericanos: Profundizando sobre la cooperación regional en Mesoamérica. Cuaderno 3: Medio Ambiente y Energía: Impacto de la Cooperación Regional Mesoamericana. San Salvador: Proyecto Mesoamérica, 2018.

Ruiz Caro, A. Los recursos naturales en los tratados de libre comercio con Estados Unidos. Washington DC: CEPAL, 2005.

Saxe, J. y Delgado, G. C. Imperialismo y Banco Mundial. Madrid: Editorial Popular, 2004.

Shiva, V. Las guerras del agua: privatización, contaminación y lucro. Madrid: Siglo XXI Editores, 2003.

Silva Pinto, F. y Cunha Marques, R. New era/new solutions: The role of alternative tariff structures in water supply projects. Water Research, 126, (2017): 216-231. DOI: 10.1016/j. watres.2017.09.023

Tortajada, C. Workshop on Water Pricing for the Americas. Water International, 27, 2(2002): 298300. DOI: $10.1080 / 02508060208687004$ 
United Nations Water. El derecho humano al agua y al saneamiento. United Nations, 2010. Recuperado de https://bit.ly/2VadQ7q

Werner, A. et al. An Initial Inventory and Indexation of Groundwater Mega-Depletion Cases. Water Resour. Manage, 27, (2013): 507-533. DOI: 10.1007/s11269-012-0199-6

Wikileaks. Tour D'Horizon with Nestlé: Forget the Global Financial Crisis, the World is Running Out of Fresh Water. Wikileaks, 24 de marzo de 2009. Recuperado de https://bit.ly/1VVDPJS

World Rainforest Movement. Principios sobre Bosques-Declaración de Principios para el Manejo Sustentable de Bosques. World Rainforest Movement, 1992. Recuperado de https://bit. ly/2CO17jh

World Rainforest Movement. El Corredor Biológico Mesoamericano: ¿conservación o apropiación? World Rainforest Movement, 2003. Recuperado de http://bit.ly/2zRFoW6

Juan Manuel Retana Céspedes. Costarricense. Licenciado en Finanzas y profesor universitario. Estudiante de Historia en la Universidad de Costa Rica.

Contacto: jmretanac@gmail.com

ORCID: 0000-0001-9025-8846

Luis Diego Arias Campos. Costarricense. Coordinador del Programa de Biología Tropical de la Escuela de la Tierra, Longo Mai, Costa Rica. Estudiante de Historia en la Universidad de Costa Rica.

Contacto: luisdiegoarias93@gmail.com

ORCID: 0000-0001-7906-7969

Daniel Torres Sandí. Costarricense. Bachiller en Sociología. Estudiante de Administración Pública en la Universidad de Costa Rica.

Contacto: tsdaniel22@hotmail.com

ORCID: 0000-0003-1147-3578 
